\title{
Article
}

\section{Using Attenuated Total Reflection (ATR) Apparatus to Investigate the Temperature Dependent Dielectric Properties of Water, Ice, and Tissue-Representative Fats}

\author{
Zoltan Vilagosh ${ }^{1, *}$, Alireza Lajevardipour ${ }^{1}$ (D), Dominique Appadoo ${ }^{2}$, Saulius Juodkazis ${ }^{3,4}$ (D) \\ and Andrew W. Wood ${ }^{1}$ (D) \\ 1 Australian Centre for Electromagnetic Bioeffects Research, Swinburne University of Technology, \\ Hawthorn, VIC 3122, Australia; alajevardipour@swin.edu.au (A.L.); awood@swin.edu.au (A.W.W.) \\ 2 Australian Synchrotron, THz Far Infrared Beamline, Clayton, VIC 3168, Australia; \\ Dominique.APPADOO@ansto.gov.au \\ 3 Optical Sciences Centre and ARC Training Centre in Surface Engineering for Advanced Materials (SEAM), \\ School of Science, Swinburne University of Technology, Hawthorn, VIC 3122, Australia; \\ saulius.juodkazis@gmail.com \\ 4 World Research Hub Initiative (WRHI), School of Materials and Chemical Technology, Tokyo Institute of \\ Technology, 2-12-1, Ookayama, Meguro-ku, Tokyo 152-8550, Japan \\ * Correspondence: zvilagosh@swin.edu.au
}

check for updates

Citation: Vilagosh, Z; Lajevardipour, A.; Appadoo, D.; Juodkazis, S.; Wood, A.W. Using Attenuated Total Reflection (ATR) Apparatus to Investigate the Temperature Dependent Dielectric Properties of Water, Ice, and Tissue-Representative Fats. Appl. Sci. 2021, 11, 2544. https://doi.org/10.3390/app11062544

Academic Editor: Roger Dorsinville

Received: 10 February 2021

Accepted: 4 March 2021

Published: 12 March 2021

Publisher's Note: MDPI stays neutral with regard to jurisdictional claims in published maps and institutional affiliations.

Copyright: (c) 2021 by the authors. Licensee MDPI, Basel, Switzerland. This article is an open access article distributed under the terms and conditions of the Creative Commons Attribution (CC BY) license (https:// creativecommons.org/licenses/by/ $4.0 /)$.

\begin{abstract}
A novel method of investigating the temperature dependent variation of aspects of the complex refractive index $\boldsymbol{n}^{*}$ in samples in the THz range using continuous, non-polarised, synchrotron radiation is presented. The method relies on the use of ATR apparatus, and retains the advantage of minimal sample preparation, which is a feature of ATR techniques. The method demonstrates a "proof of concept" of monitoring temperature reflectance whilst continuously heating or cooling samples by using a temperature variable Thermal Sample Stage. The method remains useful when the refractive index of the sample precludes attenuated total reflection study. This is demonstrated with the water reflectance experiments. The temperature dependent ATR reflectance of tissue-representative fats (lard and Lurpak ${ }^{\circledR}$ butter) was investigated with the novel approach. Both are within the ATR range of the diamond crystal in a "true" ATR mode. Lard showed no clear temperature variation between $-15^{\circ} \mathrm{C}$ and $24^{\circ} \mathrm{C}$ at 0.7 to $1.15 \mathrm{THz}$ or 1.70 to $2.25 \mathrm{THz}$. Lard can be regarded as having invariable, constant, dielectric properties within mixtures when biological substances are being assessed for temperature dependent dielectric variation within the stated $\mathrm{THz}$ ranges. Lurpak ${ }^{\circledR}$ butter (water content $14.7 \%$ ) displayed temperature dependent reflected signal intensity features with a steady decline in reflectivity with increasing temperature. This is in line with the temperature-dependent behaviour of liquid water. There is no rapid change in reflected signal intensity even at $-20{ }^{\circ} \mathrm{C}$, suggesting that emulsified water retains liquid-water-like $\mathrm{THz}$ properties at freezing temperatures.
\end{abstract}

Keywords: ATR; THz; synchrotron radiation; biological tissues; temperature variation

\section{Introduction \\ Overview}

Terahertz radiation $(\mathrm{THz})$ is highly absorbed by liquid water and this presents the possibility to image biological materials using the difference in water content between normal and pathological lesions [1]. Efforts have been made in the past to evaluate $\mathrm{THz}$ properties of biological tissues with a view to devising diagnostic imaging techniques [2-4]. The small-scale variability of biological tissue produces large "normal" ranges for $\mathrm{THz}$ dielectric parameters, which have substantial overlaps with the dielectric parameters of diseased tissue [5]. THz examination can also be time consuming and involves highly specialised expertise. These problems have resulted in difficulties in devising a diagnostic test which is both clinically relevant and practical. 
This paper examines the viability of investigating biological tissues by employing the temperature dependent variation of $\mathrm{THz}$ dielectric parameters using an attenuated total reflection (ATR) apparatus, in both the "true" attenuated total reflection mode and in a novel "reflection/transmission" mode. The Australian Synchrotron's THz-far infrared beamline provides a high brightness source, which results in rapid evaluation, enhanced spectral quality and superior spatial resolution when compared to a conventional source. Useful data can be obtained in spectral scan blocks of 30 sec or less, with the beam running $24 \mathrm{~h}$ per day. The Synchrotron's beam is continuous which makes it unsuitable for time domain spectroscopy, thus novel approaches are needed to maximise its utility. The synchrotron ATR apparatus is equipped with a diamond crystal, which has a refractive index $(n)$ of 2.40 , and since $n$ of water at THz frequencies is in the order of 1.95 to 2.15 , the setup is ideal to determine the dielectric properties of water-based compounds by using the novel "reflection/transmission" technique [6].

In terms of $\mathrm{THz}$ dielectric parameters, biological tissues can be broadly classified into two types. The "high bulk water content" tissues (over 70\%), are tissues in which a major part of the $\mathrm{THz}$ dielectric properties is dependent on the bulk (non-bound) water concentration. Examples are heart muscle ( $78 \%$ bulk water) and liver ( $78 \%$ bulk water), [7]. These tissues have an $n$ in the 1.80 to 2.30 range at $\mathrm{THz}$ frequencies. The low water content tissues, such as adipose ( $15 \%$ to $40 \%$ bulk water, [8] and cortical bone $(\sim 30 \%$ bulk water, [9]), have a major part of the THz dielectric properties dependent on non-bulk water constituents. These tissues have an $n$ in the 1.30 to 1.65 range at $\mathrm{THz}$ frequencies. Non-bulk-water constituents with important $\mathrm{THz}$ dielectric parameters include lipids, melanin, collagen, keratin and bound water.

Bound water in biological tissues is either hydrogen bonded to proteins and other polar molecules or a loose envelope surrounding the central molecule. Bound water has fewer degrees of freedom, and behaves differently to bulk water, and this is reflected in $\mathrm{THz}$ dielectric parameters. The binding of water has the equivalent effect on dielectric parameters to reducing the temperature of bulk water, however bound water is also prevented from freezing at bulk water freezing points.

The hypothesis central to the novel method is that $\mathrm{THz}$ dielectric parameters of the constituents of biological tissues will vary with temperature and with $\mathrm{THz}$ frequency, and that this variation can be clinically useful. Many disease states lead to changes in cellular components. In particular, cancers tend to have increased concentrations of bulk water. For example, the bulk water content of melanoma is in the region of $80-85 \%$, compared to $70-72 \%$ in normal skin [10]. Temperature dependent variation of $\mathrm{THz}$ dielectric parameters in biological tissues has been reported by several authors [11-13]. The reported data are typically limited to frequencies of less than 1.2 to $1.5 \mathrm{THz}$.

A unique feature of ice in the $0.1-2.0 \mathrm{THz}$ radiation window is that it has an absorption coefficient $(\alpha)$ that is much less than that of liquid water [14-18]. For example, $\alpha$ of ice is in the order of $5.0 \mathrm{~cm}^{-1}$ compared to $150-200 \mathrm{~cm}^{-1}$ for liquid water at $\sim 1.0 \mathrm{THz}$, and $50 \mathrm{~cm}^{-1}$ compared to $300 \mathrm{~cm}^{-1}$ at $2.0 \mathrm{THz}$. The non-bulk-water elements do not show the same change in $\alpha$ on freezing as bulk water does. Thus, when biological tissues are frozen, the bulk water content changes from being the principal absorber, to becoming a minor contributor to the absorption of $\mathrm{THz}$ radiation. It is imperative that accurate, temperature dependent, $\mathrm{THz}$ dielectric properties of frozen and non-frozen biological tissues be better understood over the 0.1 to $2.0 \mathrm{THz}$ band. The variation in these dielectric properties may provide insights into the nature of the tissues that is not available with other investigation modalities. Such new techniques would complement the established tissue characterisation methods. Current tissue characterisation techniques tend to depend on the interpretation of the tissue appearance of $X$-ray, visible light or ultrasound images. The potential advantage in studying the frequency dependent, temperature dependent, changes in $\mathrm{THz}$ dielectric parameters of biological tissues is that a system of characterisation of the tissues can be developed which is dependent only on the capacity of the apparatus at hand, thus reducing the need for subjective operator interpretation. When an attenuated total reflection (ATR) 
apparatus is coupled with a temperature variation apparatus, the tissue characterisation does not depend on interpretation, but simply a comparison to an established dataset. The ATR/temperature variation apparatus thus offers the ability for rapid characterisation of the tissues with minimal preparation and minimal operator training. The Synchrotron's high brightness source facilitates the systematic application of this method by offering rapid evaluation, high spectral quality and excellent spatial resolution.

\section{Attenuated Total Reflection}

The technique of attenuated total reflection (ATR) spectroscopy has become a popular method to evaluate the dielectric properties of materials. It relies on the reduction in the reflected signal intensity at an angle of incidence where total reflection occurs at the crystal/sample interface. The technique relies on some of the incident energy being absorbed when an evanescent wave is generated in the sample.

The advantage of the method lies in the fact that solid and liquid samples can be studied with minimal preparation, since the only requirement is that a sample comes into secure contact with the crystal. The equations governing the reflection of an incident wave in ATR are outlined in Hansen, [19].

The Hansen equations take account of the angle of incidence and the complex refractive index of the sample $\left(n_{2}{ }^{*}\right)$ and the crystal $\left(n_{1}{ }^{*}\right)$. The complex refractive index $\left(n^{*}\right)$ is defined as $n^{*}=n+i k$, where $n$ and $k$ are the real and imaginary part of the refractive index, respectively. The term $k$ is related to the absorption coefficient $(\alpha)$ via the equation $k=\alpha \lambda / 4 \pi$, where $\lambda$ is the wavelength of the radiation. It is apparent from the equations that there is a set of refractive index/absorption coefficient combinations which can satisfy a given reflectance; no unique pair of $n$ and $\alpha$ can be deduced from reflectance alone if a synchrotron-like continuous, non-polarised beam is used.

The combinations are dependent on frequency and angle of incidence. Examples of the combinations of sample refractive index $n_{1}$ and sample $\alpha$ at $0.3 \mathrm{THz}$ and $1.0 \mathrm{THz}$, at $45^{\circ}$ angle of incidence and a diamond crystal $\left(n_{2}=2.40\right)$ are set out in Table 1.

Table 1. A sample of the $n$ and $\alpha$ combinations at $0.3 \mathrm{THz}$ and $1.0 \mathrm{THz}$ which deliver the same reflected signal intensity at $45^{\circ}$ incidence.

\begin{tabular}{|c|c|c|c|c|c|c|c|}
\hline \multicolumn{2}{|c|}{ Frequency } & \multirow{2}{*}{$\frac{\alpha}{\mathrm{cm}^{-1}}$} & \multirow{2}{*}{$\frac{n_{1}}{\text { Silicon }}$} & \multirow{2}{*}{$\begin{array}{c}n_{2} \\
\text { Sample }\end{array}$} & \multirow{2}{*}{ S-Pol. } & \multirow{2}{*}{$\frac{\text { Reflectance }}{\text { P-Pol. }}$} & \multirow{2}{*}{ Non-Pol. } \\
\hline & & & & & & & \\
\hline water & 0.9 & 190 & 3.42 & 2.10 & 0.60 & 0.36 & 0.48 \\
\hline ice & 0.9 & 10 & 3.42 & 1.78 & 0.74 & 0.55 & 0.65 \\
\hline water & 2.0 & 300 & 3.42 & 1.95 & 0.53 & 0.28 & 0.41 \\
\hline ice & 2.0 & 50 & 3.42 & 1.78 & 0.55 & 0.30 & 0.42 \\
\hline
\end{tabular}

The example of the change from $\boldsymbol{n}_{\mathbf{2}}=1.1$ to $\boldsymbol{n}_{\mathbf{2}}=1.65$ with a change in the absorption coefficient from $\alpha=5 \mathrm{~cm}^{-1}$ to $\alpha=65 \mathrm{~cm}^{-1}$ to deliver a constant normalised reflected signal intensity of 0.79 at $1.0 \mathrm{THz}$ is illustrated in Figure 1.

The changes in reflected signal intensity can come about with changes in either parameter, $\boldsymbol{n}_{\mathbf{2}}$ or $\boldsymbol{\alpha}$. Furthermore, changes in $\boldsymbol{n}_{\mathbf{2}}$ and $\boldsymbol{\alpha}$ can either act to produce a synergistic reflectance change (when both $\boldsymbol{n}_{2}$ and $\alpha$ are simultaneously increasing or decreasing) or negate any reflectance change when one parameter is increasing and the other decreasing.

Attenuated total reflection produces an evanescent wave in the sample. The penetration depth $\left(\boldsymbol{d}_{p}\right)$ of the evanescent wave is given by [20]:

$$
d_{p}=\frac{\lambda}{2 \pi n_{2} \sqrt{\sin ^{2} \theta-\left(\frac{n_{2}}{n_{1}}\right)^{2^{\infty}}}}
$$

where $\lambda$ is the wavelength of the incident radiation in air, $n_{1}$ and $n_{\mathbf{2}}$ are the real parts of the refractive index of the ATR crystal and sample, respectively, and $\theta$ is the angle of incidence 
of the incoming radiation beam. A limit to the refractive index of the sample is evident from the equation. Since the expression $\sin ^{2} \theta-\left(n_{2} / n_{1}\right)^{2}$ has to be a real number, $\sin \theta$ needs to be $>\left(n_{2} / n_{1}\right)$. This property sets the limit on the refractive index of the sample that can be examined with attenuated total reflectance. Since it is dependent on $\theta$ and $n_{1}$ such limits are specific for a given ATR crystal at a given incident beam angle. When $\sin ^{2} \theta<\left(n_{2} / n_{1}\right)$, Equation (1) breaks down, and the incoming radiation is partially reflected and partially admitted to the sample at the crystal/sample interface as a traveling wave, i.e., there is no longer "total reflection".

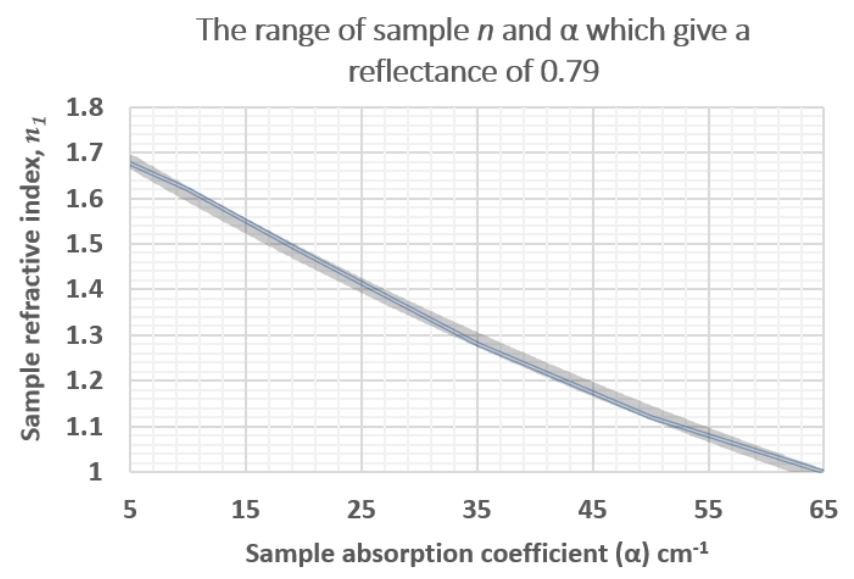

Figure 1. Illustration of the set of sample $\alpha=5 \mathrm{~cm}^{-1}$ to $\alpha=65 \mathrm{~cm}^{-1}$ and sample $n_{2}=1.1$ to $n_{2}=1.65$ which deliver a constant normalised reflectance of 0.79 at $1.0 \mathrm{THz}$ with a diamond crystal at $45^{\circ}$ angle of incidence.

The practical result is a reduction in the signal reaching the ATR detector, and the reflected signal is now solely dependent on the Fresnel reflection equations. The ATR apparatus in this instance, i.e., where $\sin ^{2} \theta<\left(n_{2} / n_{1}\right)^{2}$, is now acting in a reflection/transmission mode, where total reflection no longer occurs. This mode is not useless. Rather than delivering a possible set of sample $n$ and $\alpha$, it now delivers the real part of the refractive index $\boldsymbol{n}$ of the sample.

There are two common choices for an ATR crystal available for the lower end of the $\mathrm{THz}$ spectrum-silicon and diamond. Silicon crystal has an $n$ of 3.42 [21] at THz frequencies. Using the Equation (1), the maximum $\boldsymbol{n}_{\mathbf{2}}$ is 2.42 . This results in most biological materials being in the "true" ATR range with an incident angle of $45^{\circ}$, since typical biological tissues at $\mathrm{THz}$ frequencies have an $n<2.3$. Intuitively, it seems that silicon crystal is a good choice, however, contrast becomes a problem.

Table 2 notes the reflectance of liquid water and ice (as a proxy for water containing biological tissues), using the Hansen equations. Silicon crystal delivers only modest contrast at $0.90 \mathrm{THz}$ and very poor contrast at $2.0 \mathrm{THz}$.

Table 2. The estimated reflectance of liquid water and ice with S, P and non-polarised THz radiation *

\begin{tabular}{ccccccc}
\hline abs coef. $(\boldsymbol{\alpha}) \mathrm{cm}^{-1}$ & 10 & 35 & 65 & 10 & 35 & 65 \\
\hline frequency THz & 0.3 & 0.3 & 0.3 & 1.0 & 1.0 & 1.0 \\
\hline sample ref index $\left(\boldsymbol{n}_{\mathbf{2}}\right)$ & 1.62 & 1.28 & 1.00 & 1.62 & 1.28 & 1.00 \\
diamond ref index $\left(\boldsymbol{n}_{\mathbf{1}}\right)$ & 2.40 & 2.40 & 2.40 & 2.40 & 2.40 & 2.40 \\
\hline reflected intensity (non-pol) & 0.49 & 0.50 & 0.52 & 0.79 & 0.79 & 0.79 \\
\hline * using the Hansen $(1965)$ equations at $0.95 \mathrm{THz}$ and $2.0 \mathrm{THz}$ with a silicon crystal $(\boldsymbol{n}=3.42)$.
\end{tabular}

Diamond crystal has an $n$ of 2.38 to 2.40 at THz frequencies, [22,23]. In the case of a diamond crystal and an incident angle of $45^{\circ}, \sin ^{2} \theta=0.5$. Thus, $\left(n_{2} / n_{1}\right)^{2}$ needs to be $<0.5$, hence $n_{2} / n_{1}<0.707$, or $n_{2}<1.70$, for the diamond crystal equipped ATR apparatus to 
function in "true" attenuated total reflectance mode. It follows that substrates with $\boldsymbol{n}>1.70$ cannot be examined in attenuated total reflectance mode with the described setup.

With $n_{2}>1.70$, the diamond crystal ATR apparatus becomes a partial reflectancepartial transmission device. In this instance, the reflected portion of the incident radiation is only dependent on the relative refractive indices on either side of the reflective surface.

The reflectance can be calculated by using the Fresnel equations, and these are silent about $\alpha$. According to the Fresnel equations, the reflectance declines rapidly as $n_{2}$ approaches $\boldsymbol{n}_{\mathbf{1}}$. Given the $\boldsymbol{n}$ of diamond crystal is $\sim 2.40$, small changes in $\boldsymbol{n}_{2}$ in the region of 1.72 to 1.90 will produce large changes in reflection giving good contrast. The relationship of contrast and $n_{2}$ with diamond crystal are presented in Figure 2.

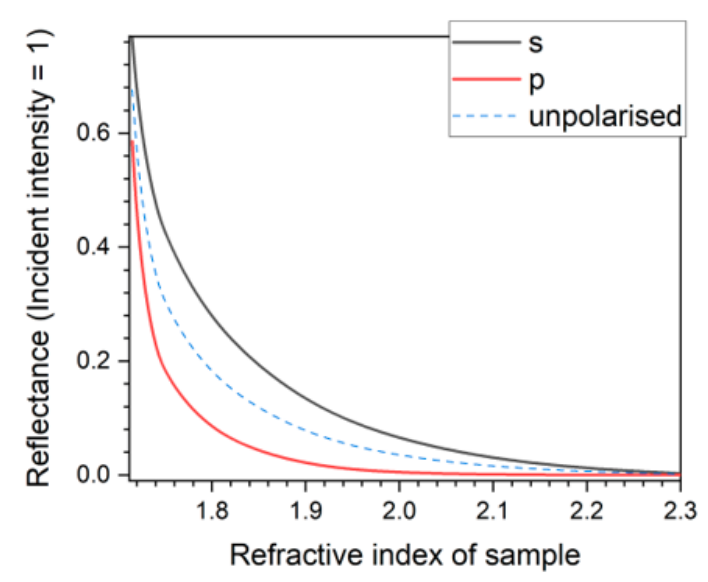

Figure 2. The normalised reflectance at the diamond/sample interface, diamond, $\boldsymbol{n}_{\mathbf{1}}=2.40$. There is significant change in the reflectance in the region of the refractive index of the sample, $\boldsymbol{n}_{\mathbf{2}}=1.72$ to 1.90 giving good contrast.

When using water and ice $\mathrm{THz}$ dielectric properties derived from literature, the Fresnel equations predict an ice to water reflectivity contrast of $\sim 300 \%$, i.e., ice is $\sim 3 \times$ more reflective than water when using a diamond crystal. The estimated Fresnel equation based reflectivity is outlined in Table 3. The refractive index of ice is not well established at $2.0 \mathrm{THz}$, and two values were used in the calculations, $n=1.78$ and $n=1.82$ at this frequency. Using the ATR as a reflectance apparatus with a diamond promises better contrast compared to silicon crystal, particularly at $2.0 \mathrm{THz}$, thus it becomes a more attractive option.

Table 3. Reflectance of liquid water and ice using the Fresnel equations at $0.90 \mathrm{THz}$ and $2.0 \mathrm{THz}$ *

\begin{tabular}{ccccccc}
\hline & \multicolumn{2}{c}{ Frequency } & & & \multicolumn{2}{c}{ Reflectance } \\
\cline { 2 - 2 } & THz & & & S-Polarised & P-Polarised & Non-Polarised \\
\cline { 5 - 7 } water & 0.9 & & 2.10 & 0.0092 & 0.000085 & 0.0046 \\
ice & 0.9 & 1.78 & 0.27 & 0.073 & 0.17 \\
\hline water & 2.0 & 1.95 & 0.076 & 0.0059 & 0.041 \\
ice & 2.0 & 1.78 & 0.27 & 0.073 & 0.017 \\
ice & 2.0 & 1.82 & 0.20 & 0.040 & 0.012 \\
\hline
\end{tabular}

* With a diamond crystal $n=2.40$. Two values for ice used, $n=1.78$ and $n=1.82$ at $2.0 \mathrm{THz}$.

There is a dichotomy with a diamond crystal ATR. At THz frequencies, biological fats and oils have an $n$ of 1.4 to 1.6. Using an ATR diamond crystal with $n$ of 2.40 results in "true" attenuated total reflection at $45^{\circ}$ incident beam with these substances. Reflectance measurements mainly deliver information regarding changes in $\alpha$. Water based biological compounds have typical $\mathrm{n}$ in the order of 1.9 to 2.2 , thus a diamond equipped ATR is acting as a partial reflection-partial transmission apparatus, delivering changes in $n$. The 
advantage of minimal sample preparation, and no requirement for thickness measurement (as would be needed for transmission studies), is retained by using the ATR apparatus in both modes.

In both cases, only a partial description of the dielectric properties is achieved. If the aim is to characterise the biological sample for the purpose of diagnosis by monitoring temperature dependent variation, then there may only be a need to find a characteristic reflected signal intensity change, rather than the full complex refractive index parameters.

\section{Materials and Methods}

The THz/Far-IR Beamline at the Australian Synchrotron, Melbourne, Australia, was used for the experiments. The Beamline was equipped with an attenuated total reflection (ATR) apparatus, a Bruker IFS 125/HR Fourier Transform spectrometer (Bremen, Germany), an Si Bolometer and a diamond prism stage $(n=2.40)$, and a $45^{\circ}$ incoming beam angle. OPUS 8.0 software (Bruker Optik GmbH, Ettlingen, Germany) was used for the initial data analysis. Air humidity was not more than $50 \%$.

The viability of monitoring temperature related changes with the ATR apparatus, both in "true" ATR mode and in partial reflection-partial transmission mode, was explored with samples with bio-medical relevance. The materials were chosen for their different hydration levels, to offer varying insights into the possible temperature related changes. The temperature dependent variation of absorbance of air, water, ice, porcine rendered lard, and Lurpak ${ }^{\circledR}$ (unsalted) butter was explored. Lurpak ${ }^{\circledR}$ butter is homogeneous, and has water, lipid and protein components. It has an additional advantage of having established dielectric properties in the $\mathrm{THz}$ range [24].

The samples were applied through a spacer to define $2 \mathrm{~mm}$ thickness (water, lard, butter). At $2 \mathrm{~mm}$, the path length of any returning signal from samples with absorption coefficients of $>20 \mathrm{~cm}^{-1}$ become negligible.

A mirrored cooling bath was placed on top of the sample and fixed by a standard ATR mounting clip onto the ATR diamond prism window. In partial reflection-partial transmission mode, with a path length of $>4 \mathrm{~mm}(2 \times 2 \mathrm{~mm}$ sample thickness $)$, any reflected signal from the mirror returning through the samples with absorption coefficients of $>10 \mathrm{~cm}^{-1}$ becomes negligible. Similarly, in "true" ATR mode, lard and Lurpak ${ }^{\circledR}$ butter have an $n \sim 1.5$ to 1.6 in the 0.9 to $1.0 \mathrm{THz}$ spectral window [24,25], which would, under ideal attenuated total refection circumstances of a negligible $\alpha$, deliver a $d_{p}$ of $<0.01 \mathrm{~mm}$. Thus, any interference from the mirror reflection back through the sample is similarly negligible.

Polarisation of synchrotron radiation is a combination of linear (along the extraction mirror slit) and circular polarisations [26]. These two components arise due to the bending magnet caused dipole-emission inside the magnet and the edge-emission at the entrance/exit of the magnet edge. The THz and IR microscopy beamlines share the synchrotron radiation extracted from the magnet. The THz/Far-IR beamline receives a larger portion of the edge-emission compared to the dipole-emission. Polarisation is defined in the plane of incidence as Es and Ep, which are perpendicular $(\perp)$ and parallel $(\mathrm{k})$ to the plane (or TE and TM modes), respectively.

The reflected radiation at the $45^{\circ}$ incidence usually does not experience phase change upon reflection at the sample-prism interface for low refractive index $\left(n_{2}<1.6\right)$ samples, which is typical for low "bulk water" biological samples. However, the P-polarised (TM; Ez) radiation, which probes the absorbance in the direction perpendicular to the prism-sample interface, has a strong dependence of the reflected phase on $n_{2}$. At $\theta i=45^{\circ}$ incidence, a phase change of $\pi$ occurs when $\theta_{B}<\theta_{i}<\theta c\left(\theta_{B}\right.$ and $\theta c$ are the Brewster and critical angle, respectively) and the reflected Ez component becomes Ey.

The consequence of the phase dependence of the TM mode makes polarisation analysis of ATR signals complicated, and most of the published data do not discriminate polarisation. This approach was adopted in the current study. Future experiments will include a defined incident polarisation combined with polarisation analysis at the exit after the sample. 
The ATR unit had a Thermal Stage fitted, with a capability to control the temperature of the sample and the crystal. The diamond ATR prism and the sample compartment were made suitable for cooling by using a bath from above the sample and also by a cooling/heating apparatus attached to the ATR bowl (Figure 3). The temperature variation was monitored with a thermocouple probe placed in contact with the sample next to the diamond crystal.

(a)

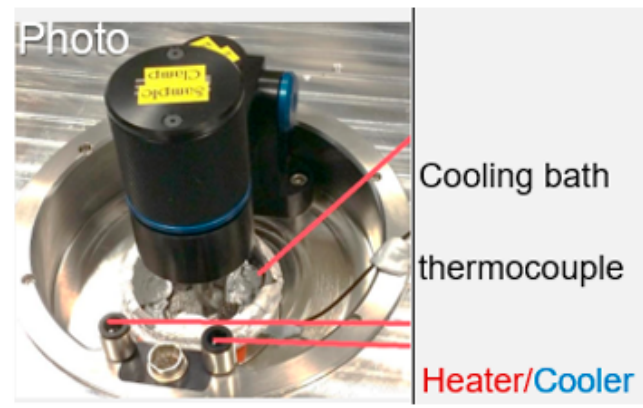

(b)

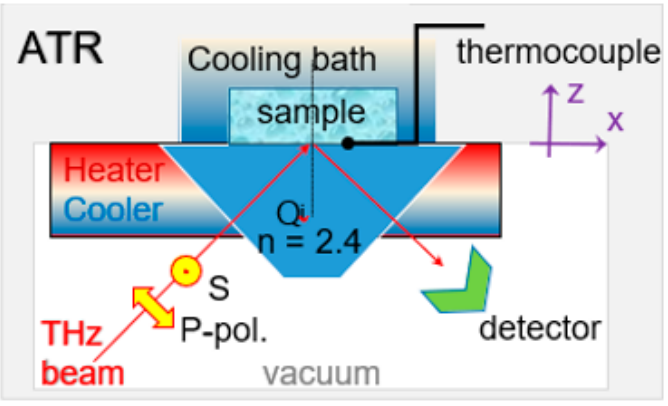

Figure 3. (a) Photo and (b) schematics of ATR setup with Thermal Stage used for temperature dependent absorbance spectroscopy at the THz/Far-IR beamline with Thermal Sample Stage attached.

The temperature variation was monitored with scans in real time, i.e., repeated scans as the temperature was changing. Due to the brightness of the Australian synchrotron $\mathrm{THz}$ source, attenuated total reflection (ATR) apparatus can produce a scan every $0.3-0.4 \mathrm{~s}$ at $\mathrm{THz}$ frequencies. Data were collected and presented with each datapoint being an average of 50 scans. This resulted in total data gathering times for each sample of 15 to $20 \mathrm{~min}$. Data analysis was carried out with the OPUS 8.0 software. The experiments were conducted over the frequency range of 0.18 to $3 \mathrm{THz}$. In practice, the useful sensitivity of the detector was in the range of wavenumber 23 to $38(\sim 0.7$ to $1.15 \mathrm{THz})$ and wavenumber 56.5 to 75.0 ( $\sim 1.70$ to $2.25 \mathrm{THz}$ ). The best sensitivity of the detector was in the range of 0.85 to $1.05 \mathrm{THz}$ and 1.85 to $2.10 \mathrm{THz}$.

\section{Results}

\subsection{Air}

The reflected signal intensity of air was measured at $20^{\circ} \mathrm{C}$, and also in 10 serial increasing increment outputs from $-24{ }^{\circ} \mathrm{C}$ to $5{ }^{\circ} \mathrm{C}$. The outputs showed no particular pattern and were within $+/-1.5 \%(0.70$ to $1.15 \mathrm{THz})+/-0.46 \%$ (1.70 to $2.25 \mathrm{THz})$ of the median value for the entire group. The air reflectivity was used to normalise the other reflectivity data.

\subsection{Water and Ice}

The reflected signal intensity of water was measured at $5{ }^{\circ} \mathrm{C}$ to $10{ }^{\circ} \mathrm{C}$ in 10 serial outputs, averaging 50 scans per individual output, using the Thermal Stage. Ice was monitored in 10 serial outputs, also averaging 50 scans per individual output using the Thermal Stage. The temperature of the ice was allowed to rise from $-25^{\circ} \mathrm{C}$ to $-15^{\circ} \mathrm{C}$. The water and ice reflected signal intensity data are presented in Figure 4 . Normalised water reflectivity (compared to air) was in the order 0.03 to 0.07 for wavenumber 23 to $38(\sim 0.70$ to $1.15 \mathrm{THz}$ ) and $\sim 0.04$ for wavenumber 56.5 to 75.0 ( 1.70 to $2.25 \mathrm{THz}$ ). 
(a)

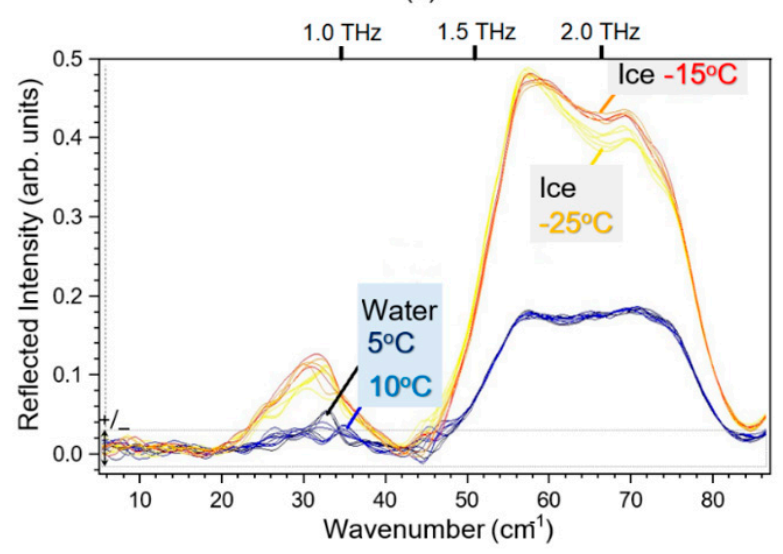

(b)

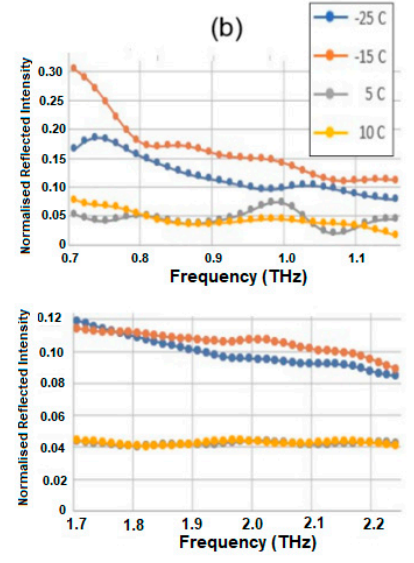

Figure 4. Raw data, spectral reflected signal intensity for water and ice. (a) Reflected signal intensity of water and ice at different temperatures in arbitrary units. Ice samples were made in situ. Each of the 10 data points is an average of 50 scans per measurement. (b) Reflected signal intensity (normalised to that of air, $\boldsymbol{n}=1$ ) at different temperatures. The two high sensitivity spectral bands centered around 0.9 and $2 \mathrm{THz}$ are shown.

Ice reflectivity showed a tighter grouping at 1.7 to $2.25 \mathrm{THz}$ and a reduction in reflectivity with increasing frequency. There was much greater consistency of data in the 1.70 to $2.25 \mathrm{THz}$ range when compared to the 0.70 to $1.15 \mathrm{THz}$ range. The results at the most reliable point of $0.9 \mathrm{THz}$ in the lower data set and at $2.0 \mathrm{THz}$ are presented in Table 4 .

Table 4. Comparison of reflected signal intensity of the experimental data from water and ice to theoretical predictions *.

\begin{tabular}{|c|c|c|c|c|}
\hline \multicolumn{3}{|c|}{ Predicted } & \multirow{2}{*}{$\begin{array}{c}\text { Experiment } \\
-25^{\circ} \mathrm{C}\end{array}$} & \multirow{2}{*}{$\frac{\text { Experiment }}{-15^{\circ} \mathrm{C}}$} \\
\hline $0.9 \mathrm{THz}$ & with $n=1.78$ & & & \\
\hline & 0.17 & & 0.15 & 0.11 \\
\hline \multirow[t]{2}{*}{$2.0 \mathrm{THz}$} & with $n=1.78$ & with $n=1.82$ & & \\
\hline & 0.17 & 0.12 & 0.095 & 0.11 \\
\hline
\end{tabular}

The measured contrast between liquid water and ice reflected signal intensity at both ranges is broadly in line with the dielectric properties data from [14-18]. The reflected signal intensity of water and ice show a decline over the 0.70 to $1.15 \mathrm{THz}$ range, but the experimental values are erratic. At $2.0 \mathrm{THz}$, the reflected signal intensity of water is flat over the measured range and does not change with temperature. The reflectance of ice declines with both frequency and temperature over the 1.70 to $2.25 \mathrm{THz}$ range. The measured reflected signal intensity of ice at $2.0 \mathrm{THz}$ is consistent with a refractive index of 1.83 , which is at the upper boundary of the literature derived data.

\subsection{Rendered Porcine Lard}

Commercially obtained rendered porcine lard was used as a sample. Rendered lard contains chiefly triacylglycerides and fatty acids, with the water, protein and fibrous tissue components of adipose tissue being removed by the production process [27]. Lard has an $n$ of 1.48 and $\alpha$ of $8 \mathrm{~cm}^{-1}$ in the 0.9 to $1.0 \mathrm{THz}$ spectral window, [25], making lard within the "true" ATR range of the diamond crystal. Lard was studied between $-15^{\circ} \mathrm{C}$ and $24^{\circ} \mathrm{C}$ with 42 individual serial outputs, each an average of 50 individual scans. The temperature was varied over a total time of 16 min with 21 discrete scanning episodes of $2 \times 50$ scans. The lard reflected signal intensity data are presented in Figure 5. 

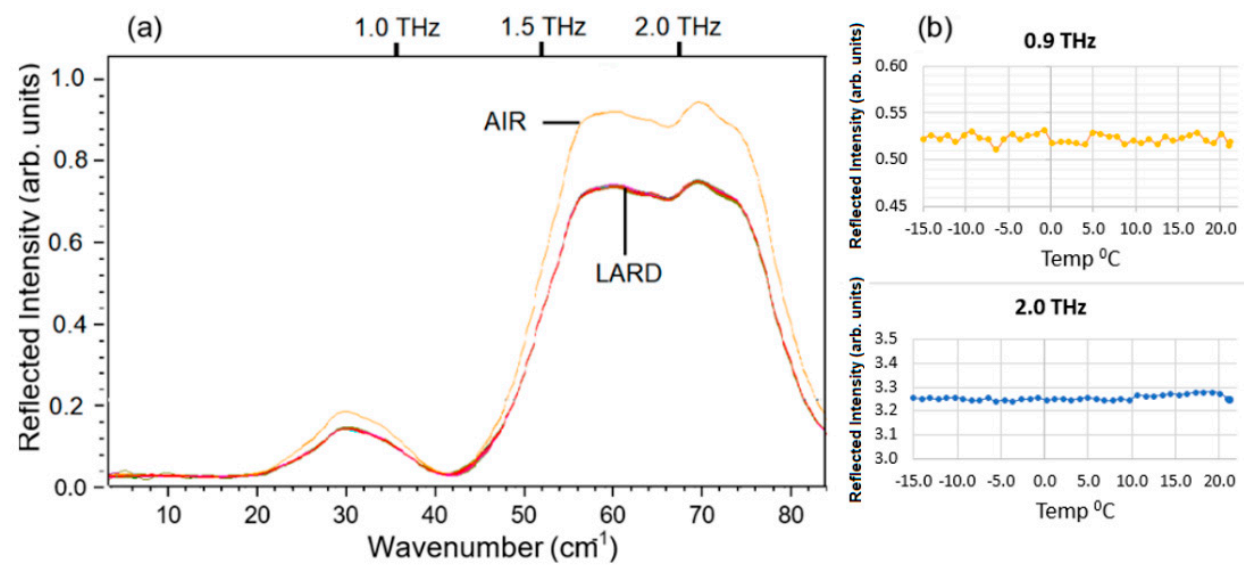

Figure 5. Raw data reflected signal intensity of lard (in arbitrary units). (a) The entire spectral range $-15^{\circ} \mathrm{C}$ to $24^{\circ} \mathrm{C}$, showing a tight grouping. (b) Spectral band centered on $0.9 \mathrm{THz}$ at $-15^{\circ} \mathrm{C}$ to $24{ }^{\circ} \mathrm{C}$. (c) Spectral band centered on $2.0 \mathrm{THz}$. The reflected signal intensity does not show any temperature variation.

Results show no clear temperature variation of reflected signal intensity at the optimal windows of wavenumber 23 to $38(\sim 0.70$ to $1.15 \mathrm{THz})$ and wavenumber 56.5 to $75.0(\sim 1.70$ to $2.25 \mathrm{THz}$ ), with all values within a +/ $-2.2 \%(0.7$ to $1.15 \mathrm{THz})$ and $+/-0.5 \%$ (1.70 to $2.25 \mathrm{THz}$ ) range, similar to the variation of the reflected signal intensity of air.

\subsection{Lurpak $^{\circledR}$ Butter}

Lurpak $^{\circledR}$ butter has a water content of $14.7 \%(w / w)$ and $3 \%(w / w)$ non-fatty solids, with the balance being triglycerides. The dielectric properties are $n=1.57$ and $\alpha=37 \mathrm{~cm}^{-1}$ at $1.0 \mathrm{THz}$ and $\boldsymbol{n}=1.55$ and $\boldsymbol{\alpha}=51 \mathrm{~cm}^{-1}$ at $1.5 \mathrm{THz}$ [24].

The thermal dependence of the dielectric properties of Lurpak ${ }^{\circledR}$ butter were investigated with a total of 140 individual serial spectral outputs between $-20^{\circ} \mathrm{C}$ and $24{ }^{\circ} \mathrm{C}$. Each output was an average of 50 scans. The temperature was varied over a total time frame of 24 min with continual scanning during the temperature variation. The raw spectral data for Lurpak ${ }^{\circledR}$ butter are presented in Figure 6. Spectral bands centred around $0.9 \mathrm{THz}$ and $2.0 \mathrm{THz}$ are shown in Figure 7.

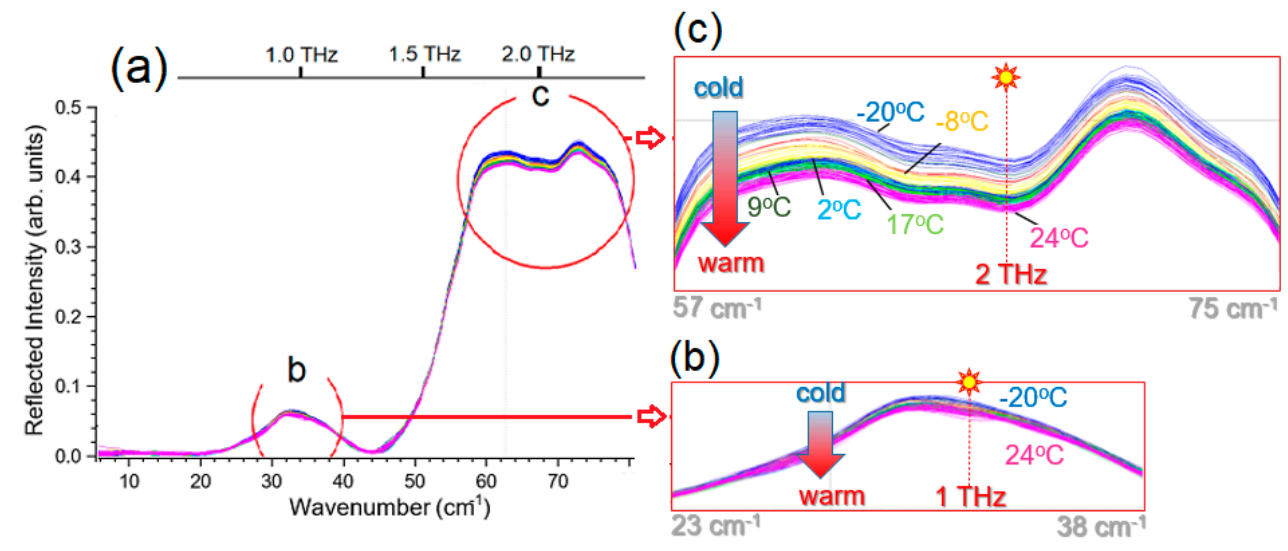

Figure 6. Raw data, spectral reflected signal intensity for Lurpak ${ }^{\circledR}$ butter. (a) Reflected signal intensity in arbitrary units from $-20^{\circ} \mathrm{C}$ to $24^{\circ} \mathrm{C}$. (b) Highlight, reflected signal intensity Lurpak ${ }^{\circledR}$ butter in the range of wavenumber 23 to $38 \mathrm{~cm}^{-1}$ ( $\sim 0.7$ to $1.15 \mathrm{THz}$ ). (c) Highlight, of Lurpak butter in the range, wavenumber 57 to $75.0 \mathrm{~cm}^{-1}$ ( $\sim 1.70$ to $\left.2.25 \mathrm{THz}\right)$. 

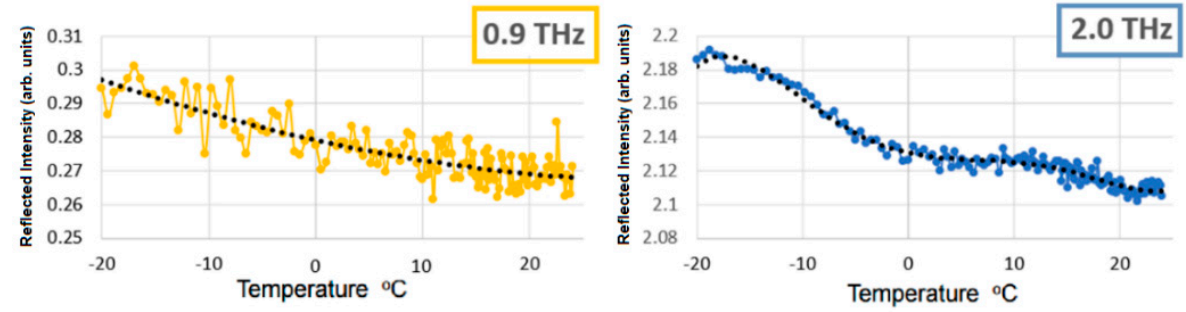

Figure 7. Spectral bands centered around 0.9 and $2.0 \mathrm{THz}$. There is a decline in reflected signal intensity with increasing temperature at both frequencies with a temperature dependent plateau over the 0 to $10{ }^{\circ} \mathrm{C}$ range at $2.0 \mathrm{THz}$.

There is a temperature dependent reduction in the, reflected signal intensity of Lurpak $^{\circledR}$ butter in the frequency range of 0.7 to $1.15 \mathrm{THz}$. There is a temperature dependent plateau over the $0{ }^{\circ} \mathrm{C}$ to $10{ }^{\circ} \mathrm{C}$ range at 1.7 to $2.2 \mathrm{THz}$, which becomes more evident with increasing frequency. Lurpak ${ }^{\circledR}$ butter shows a $13 \%$ decrease in, reflected signal intensity between $-20^{\circ} \mathrm{C}$ and $24^{\circ} \mathrm{C}$, at $0.9 \mathrm{THz}$, and a $3.5 \%$ decrease in, reflected signal intensity between $-20^{\circ} \mathrm{C}$ and $24^{\circ} \mathrm{C}$, at $2.0 \mathrm{THz}$.

Lurpak $^{\circledR}$ butter displays temperature dependent reflected signal intensity which is not the featureless reflected signal intensity of lard. There is a steady decline in reflectivity with increasing temperature suggesting an increase in $\alpha$ in line with the temperature dependent behaviour of liquid water (the temperature dependent $\alpha$ changes in ice are not well documented). There is no sudden change in reflected signal intensity which would suggest a change of state of the constituent water, even at $-20^{\circ} \mathrm{C}$, but, as noted, there is a plateau in the $0{ }^{\circ} \mathrm{C}$ to $10^{\circ} \mathrm{C}$ range at $\sim 2.0 \mathrm{THz}$, suggestive of some phase related transformation.

\section{Discussion}

Three items of scientific interest emerge from the presented methods and data. The first is a novel method of investigating the temperature dependent variation of the dielectric parameters in samples in the $\mathrm{THz}$ range using continuous, non-polarised, synchrotron radiation. The method is shown to be useful over a range of sample types, and over a range of temperatures. The method relies on the use of ATR apparatus, and retains the advantage of minimal sample preparation, which is a feature of ATR methods. The ability for rapid measurement with a bright synchrotron source demonstrates a "proof of concept" of rapidly monitoring temperature dependent changes in reflectance whilst continuously heating or cooling the sample by using a temperature variable Thermal Stage.

The second item is the novel method's ability to retain the ATR advantages with samples where the refractive index leaves the ATR apparatus to no longer act in a "true" attenuated total reflection mode, but in a reflection/transmission mode. The ability of an ATR apparatus to usefully act as a reflectance/transmission apparatus in the instances where the refractive index of the sample precludes attenuated total reflection study is demonstrated with the water reflectance experiments. The ATR can only return a refractive index in this mode and further modification of technique, such as a mirror reflector at a small distance [6] is required to extract the absorption coefficient in these circumstances. The reflected signal intensity of water in the experiments suggests that the reflection from the crystal/sample interface in the transmitted mode is non-polarised. Remarkably, reflected signal intensity changes of ice in the 1.70-2.25 THz band were recognisable between $-25^{\circ} \mathrm{C}$ and $-15^{\circ} \mathrm{C}$. The changes of refractive index in ice are not well known in the $\mathrm{THz}$ frequency range and the techniques described in this paper open the possibility to accurately document these fundamental properties. The experimental results were in line with the predicted numbers from theoretical calculation and literature data.

The third item is the demonstration of the a "proof of concept" of estimating temperature dependent ATR reflected signal intensity of lard and Lurpak ${ }^{\circledR}$ butter. Both are within the ATR range of the diamond crystal in a "true" ATR mode. Lard was studied in the range $-15{ }^{\circ} \mathrm{C}$ and $24^{\circ} \mathrm{C}$ with results showing no clear temperature related change at either the 
0.7 to $1.15 \mathrm{THz}$ or the 1.70 to $2.25 \mathrm{THz}$ range, with the variation staying in the error range of the air calibration (within $+/-1.5 \%(0.70$ to $1.15 \mathrm{THz})+/-0.46 \%)$. This suggests that lipids can be regarded as having invariable, constant, dielectric properties within mixtures when biological substances are being assessed for temperature dependent dielectric variation.

Lurpak $^{\circledR}$ butter has a water content of $14.7 \%(w / w)$, approximating adipose tissue $\left(\sim 15 \%\right.$ bulk water). Lurpak ${ }^{\circledR}$ butter displays temperature dependent reflected signal intensity features, with a steady decline in reflectivity with increasing temperature. Given that Lurpak ${ }^{\circledR}$ butter has a refractive index within the "true" attenuated total reflectance of the diamond crystal equipped ATR, the result suggests an increase in the absorption coefficient with increasing temperature. There is no rapid change in reflected signal intensity which would suggest a change of state even at $-20^{\circ} \mathrm{C}$. The contribution of the protein fraction of Lurpak ${ }^{\circledR}$ butter has not yet been determined.

\section{Conclusions and Outlook}

The flexibility and capacity of ATR apparatus, when coupled with a bright THz source such as the Australian Synchrotron, offers a range of possibilities which are beyond its strict capacity as an apparatus for measuring attenuated total reflection. This paper has demonstrated the use of the ATR as a reflectance/transmission apparatus and the capacity for apparatus to study temperature related changes in samples. Both novel functions can be performed quickly and reliably. This raises the possibility of finding "signatures" for clinically relevant biological tissues and disease states. In turn, this can lead to rapid diagnostic applications which rely on tissue properties which are not being assessed by other means. Since the reflectance of ice and water with the diamond crystal in the reflection/transmission mode is solely dependent on the refractive index, the outlined method can be used to accurately map the temperature and frequency variation of the refractive index of ice to a high degree of precision.

The next challenge is to provide methods to "fill in the gaps", with the need to evolve a rapid and reliable way to extract the complex refractive index with the ATR apparatus whilst using an incoherent bright $\mathrm{THz}$ source, and similarly the absorption coefficient in the instance when the ATR apparatus is performing in reflectance/transmission mode. There is also the pressing need to produce more background temperature variability data on biological tissues.

Author Contributions: Conceptualization, Z.V. methodology, Z.V., A.W.W.; software, Z.V., A.L.; validation, D.A., S.J., and A.W.W.; formal analysis, Z.V.; investigation, Z.V.; resources, D.A., S.J, A.W.W.; data curation, Z.V.; writing—original draft preparation, Z.V.; writing—review and editing, A.L., Z.V., A.W.W.; visualization, Z.V.; supervision, A.L., A.W.W.; project administration, S.J., A.W.W.; funding acquisition, A.W.W. All authors have read and agreed to the published version of the manuscript.

Funding: This research was funded by in-kind ANSTO Grant, Reference No: AS193/THz/15578.

Institutional Review Board Statement: Not applicable.

Informed Consent Statement: Not applicable.

Data Availability Statement: Upon reasonable request, the corresponding author is ready to share.

Acknowledgments: The authors would like to acknowledge the help and advice offered by Ruth Plathe, Scientific Support Officer at the Australian Synchrotron.

Conflicts of Interest: The authors declare no conflict of interest.

\section{References}

1. Vilagosh:, Z.; Lajevardipour, A.; Wood, A.W. Computational phantom study of frozen melanoma imaging at 0.45 terahertz. Bioelectromagnetics 2019, 40, 118-127. [CrossRef] [PubMed]

2. Wallace, V.P.; Fitzgerald, A.J.; Pickwell, E.; Pye, R.J.; Taday, P.F.; Flanagan, N.; Ha, T. Terahertz pulsed spectroscopy of human basal cell carcinoma. Appl. Spectrosc. 2006, 60, 1127-1133. [CrossRef]

3. Ashworth, P.C.; Pickwell-MacPherson, E.; Provenzano, E.; Pinder, S.E.; Purushotham, A.D.; Pepper, M.; Wallace, V.P. Terahertz pulsed spectroscopy of freshly excised human breast cancer. Opt. Express 2009, 17, 12444-12454. [CrossRef] 
4. Fitzgerald, A.J.; Wallace, V.P.; Pinder, S.E.; Purushotham, A.D.; O'Kelly, P.; Ashworth, P.C. Classification of terahertz-pulsed imaging data from excised breast tissue. J. Biomed. Opt. 2012, 17, 016005. [CrossRef] [PubMed]

5. Gavdush, A.; Chernomyrdin, N.; Komandin, G.; Dolganova, I.N.; Nikitin, P.V.; Musina, G.R.; Katyba, G.M.; Kucheryavenko, A.S.; Reshetov, I.V.; Potapov, A.; et al. Terahertz dielectric spectroscopy of human brain gliomas and intact tissues ex vivo: Double-Debye and double-overdamped-oscillator models of dielectric response. Biomed. Opt. Express 2021, 12, 69. [CrossRef] [PubMed]

6. Vilagosh, Z.; Lajevardipour, A.; Appadoo, D.; Ng, S.H.; Juodkazis, S.; Wood, A.W. Char-acterisation of Biological Materials at THz Frequencies by Attenuated Total Reflection: Lard. Appl. Sci. 2020, 10, 8692. [CrossRef]

7. Lee, K.; Jeoung, K.; Kim, S.H.; Ji, Y.-B.; Son, H.; Choi, Y.; Huh, Y.-M.; Suh, J.-S.; Oh, S.J. Measuring water contents in animal organ tissues using terahertz spectroscopic imaging. Biomed. Opt. Express 2018, 9, 1582-1589. [CrossRef] [PubMed]

8. Baker, G.L. Human Adipose Tissue Composition and Age. Am. J. Clin. Nutr. 1969, 22, 829-835. [CrossRef]

9. Provyn, S.; Clarys, J.P.; Wallace, J.; Scafoglieri, A.; Reilly, T. Quality Control, Accuracy, and Prediction Capacity of Dual Energy X-ray Absorptiometry Variables and Data Acquisition. J. Physiol. Anthr. 2008, 27, 317-323. [CrossRef]

10. Gniadecka, M.; Nielsen, O.; Wulf, H. Water content and structure in malignant and benign skin tumours. J. Mol. Struct. 2003, 661-662, 405-410. [CrossRef]

11. Sim, Y.C.; Park, J.Y.; Ahn, K.-M.; Park, C.; Son, J.-H. Terahertz imaging of excised oral cancer at frozen temperature. Biomed. Opt. Express 2013, 4, 1413-1421. [CrossRef]

12. He, Y.; Ung, B.S.-Y.; Parrott, E.P.J.; Ahuja, A.T.; Pickwell-MacPherson, E. Freeze-thaw hysteresis effects in terahertz imaging of biomedical tissues. Biomed. Opt. Express 2016, 7, 4711-4717. [CrossRef] [PubMed]

13. Yanina, I.Y.Y.; Nikolaev, V.; Zakharova, O.A.; Borisov, A.; Dvoretski, K.N.; Berezin, K.V.; Kochubey, V.I.; Kistenev, Y.V.; Tuchin, V.V. Measurement and modeling of optical properties of heated adipose tissue in the terahertz range. Terahertz Photonics 2020, 11348, 1134817. [CrossRef]

14. Hasted, J.; Husain, S.; Frescura, F.; Birch, J. The temperature variation of the near millimetre wavelength optical constants of water. Infrared Phys. 1987, 27, 11-15. [CrossRef]

15. Liebe, H.; Hufford, G.; Manabe, T. A model for the complex permittivity of water at fre-quencies below $1681 \mathrm{THz}$. Int. J. Infrared Millim. Waves 1991, 12, 659-675. [CrossRef]

16. Zhang, C.; Lee, K.-S.; Zhang, X.-C.; Wei, X.; Shen, Y. THz spectroscopy of ice. Lasers Electro Opt. Soc. IEEE 2002,2 , $646-647$.

17. Woodward, R.M.; E Cole, B.; Wallace, V.P.; Pye, R.J.; Arnone, D.D.; Linfield, E.H.; Pepper, M. Terahertz pulse imaging in reflection geometry of human skin cancer and skin tissue. Phys. Med. Biol. 2002, 47, 3853-3863. [CrossRef] [PubMed]

18. Ashworth, P.; Zeitler, J.; Pepper, M.; Wallace, V. Terahertz spectroscopy of biologically relevant liquids at 175 low temperatures. In Proceedings of the Infrared Millimeter Waves and 14th International Conference on Teraherz Electronics, Shanghai, China, 18-22 September 2006; p. 184.

19. Hansen, W.N. Expanded formulas for attenuated total reflection and the derivation of ab-sorption rules for single and multiple ATR spectrometer cells. Spectrochim. Acta 1965, 21, 815-833. [CrossRef]

20. Ramer, G.; Lendl, B. Attenuated Total Reflection Fourier Transform Infrared Spectroscopy. In Encyclopedia of Analytical Chemistry: Online; John Wiley and Sons, Ltd.: Berlin, Germany, 2013.

21. Dai, J.; Zhang, J.; Zhang, W.; Grischkowsky, D. Terahertz time-domain spectroscopy char-acterization of the far-infrared absorption and index of refraction of high-resistivity, float-zone silicon. JOSA B 2004, 21, 1379-1386. [CrossRef]

22. Kubarev, V.V. Optical properties of CVD-diamond in terahertz and infrared ranges. Nucl. Instrum. Methods Phys. Res. Sect. A Accel. Spectrometers De-tectors Assoc. Equip. 2009, 603, 22-24. [CrossRef]

23. Amma, S.I.; Luo, J.; Pantano, C.G.; Kim, S.H. Specular reflectance (SR) and attenuated total reflectance (ATR) infrared (IR) spectroscopy of transparent flat glass surfaces: A case study for soda lime float glass. J. Non-Cryst. Solids 2015, 428, 189-196. [CrossRef]

24. Møller, U.; Folkenberg, J.R.; Jepsen, P.U. Dielectric Properties of Water in Butter and Water-AOT-Heptane Systems Measured Using Terahertz Time-Domain Spectroscopy. Appl. Spectrosc. 2010, 64, 1028-1036. [CrossRef] [PubMed]

25. Reid, C.B.; Pickwell-MacPherson, E.; Laufer, J.G.; Gibson, A.P.; Hebden, J.C.; Wallace, V.P. Accuracy and resolution of THz reflection spectroscopy for medical imaging. Phys. Med. Biol. 2010, 55, 4825-4838. [CrossRef] [PubMed]

26. Ryu, M.; Linklater, D.P.; Hart, W.; Balcytis, A.; Skliutas, E.; Malinauskas, M.; Appadoo, D.; Tan, Y.-R.E.; Ivanova, E.P.; Morikawa, J.; et al. 3D printed polarizing grids for IR-THz synchrotron radiation. J. Opt. 2018, 20, 035101. [CrossRef]

27. Rohman, A.; Triyana, K.; Erwanto, Y. Differentiation of lard and other animal fats based on triacylglycerols composition and principal component analysis. Int. Food Res. J. 2012, 19, 475-479. 